\title{
Regulation of the absorption of dietary carbohydrate in man by two new glycosidase inhibitors
}

\author{
R H TAYLOR, HELEN M BARKER, ELIZABETH A BOWEY, \\ AND JEAN E CANFIELD \\ From the Department of Gastroenterology and Nutrition, Central Middlesex Hospital, London
}

SUmmary Two new reversible inhibitors of intestinal $\alpha$-glycosidases (BAY m1099 \& o1248) have been derived from deoxynojirimycin. Their inhibitory substrate specificity has been investigated in man using test meals of the dietary carbohydrates, sucrose, maltose, and starch. Both inhibitors abolished the postprandial glycaemic rise after sucrose and m $109950 \mathrm{mg}$ did after maltose and starch, whereas $0124820 \mathrm{mg}$ had no effect after maltose and only a small effect after starch. Breath hydrogen evolution, as an indirect measure of malabsorption, showed that the reduced glycaemic responses, particularly after sucrose, were associated with considerable substrate malabsorption. Dose response studies showed that lower doses of both inhibitors could reduce postprandial glycaemia significantly without causing malabsorption. Both inhibitors were tolerated well. These two new enzyme inhibitors have different substrate specificity in man and can, in appropriate dose, regulate postprandial glycaemia by selective inhibition of brush border enzymes without causing malabsorption. In addition to their therapeutic importance, they provide a valuable experimental model of specific intestinal enzyme deficiency states.

The postprandial rise in blood glucose is determined by a number of dietary, gastrointestinal, hormonal, and metabolic factors. The amount of available carbohydrate; ${ }^{1}$ its physical form ${ }^{2}$ and complexity; ${ }^{3}$ the presence of dietary protein ${ }^{+}$fat $^{5}$ and dietary fibre $^{\prime}$ in the meal are all important dietary determinants of the rate of absorption. Abnormalities of the small intestinal mucosa and enzyme deficiencies can slow digestion and thus absorption. The rates of hepatic carbohydrate metabolism, insulin release, and peripheral glucose uptake also regulate blood glucose levels.

Awareness of the importance of close control of blood glucose concentrations in reducing the long term complications of diabetes stimulated research into new ways of stabilising postprandial glycaemia. One approach to this has been by the use of specific inhibitors of the intestinal $\alpha$-glycosidase hydrolases, because all dietary carbohydrate, with the exception of lactose, is digested by these intestinal enzymes. There are many naturally occurring substances which inhibit these enzymes, but most are complex

Address for correspondence: Dr R H Taylor. Dept of (iastroenterology and Nutrition, Central Middlesex Hospital. Acton lane. London NWI0 7NS

Received for publication 22 April 1986 proteins or carbohydrates and are unstable, nonspecific or irreversible.

The first pure synthetic glycoside hydrolase inhibitor was the pseudotetrasaccharide acarbose (Fig. 1a) which was isolated from culture of various genera of Actinomycetes. ${ }^{7}$ It is a stable compound and a powerful inhibitor of sucrase and maltase activity in vitro ${ }^{89}$ and in vivo in the rat ${ }^{10}$ and in man. ${ }^{11}$ It was the first inhibitor to be shown to have a reversible effect in the short term ${ }^{12}{ }^{13}$ and it has no effect on monosaccharide transport mechanisms. ${ }^{14}$ Stable partial inhibition of sucrase activity can be obtained with this inhibitor ${ }^{15}$ in which the rate of onset and the steady state are dose related. ${ }^{16}$ In test meal studies in man with acarbose the glycaemic response to sucrose was greatly reduced, that to starch was moderately impaired, and to maltose was reduced slightly. The reduction in glycaemic response was associated with evidence of carbohydrate malabsorption. ${ }^{11}$

Two new $\alpha$-glycoside hydrolase inhibitors derived from 1-deoxynojirimycin have now been synthesised in microbial culture. Both nojirimycin (Fig lb), synthesised by various species of Streptomyces and strains of the genus Bacillus, and its reduced form, 1-deoxynojirimycin (Fig lc), are potent inhibitors 

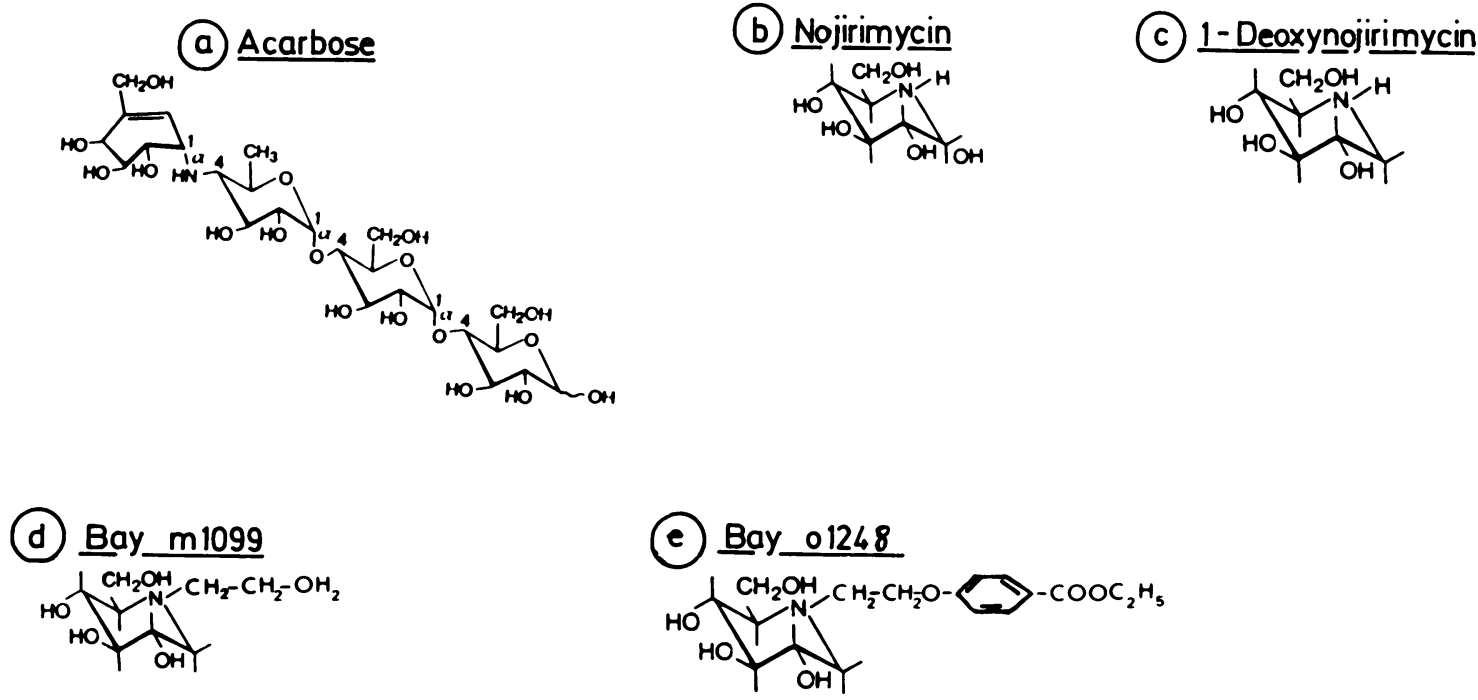

Fig. 1 Structure of acarbose, nojirimycin, I-deoxynojirimycin and the deoxynojirimycin derivatives, BAY ml099 and ol248.

of mammalian intestinal brush border $\alpha$-glycoside hydrolases in vitro, but not of $\alpha$-amylase. ${ }^{8-21}$ Two derivatives of 1-deoxynojirimycin with modified side chains, designated BAY m1099 and o1248, have been produced (Figs 1d,e). Both are potent inhibitors of specific rat intestinal $\alpha$-glycoside hydrolases in vitro. ${ }^{22}$ In studies of intestinal perfusion in the rat in vivo the inhibitors have been shown to have reversible effects and to have different patterns of substrate specificity. ${ }^{23-25}$

In these studies the two new inhibitors have been used in man firstly to establish their substrate specificity and secondly to find dose levels at which postprandial blood glucose concentrations are controlled by slowing absorption, without causing malabsorption of dietary carbohydrate with its associated symptoms of flatulence, distension, and osmotic diarrhoea.

\section{Methods}

SUBSTRATE SPECIFICITY STUDY

Six healthy male subjects (mean age 30 years, range $27-33 ; 111 \%$, range $84-130 \%$ desirable weight $\left.{ }^{2 n}\right)$ took nine oral $50 \mathrm{~g}$ carbohydrate tolerance tests consisting of sucrose, maltose or starch with $4(0) \mathrm{ml}$ water. In order to give a palatable and representative form of dietary starch, instant mashed potato was used (Winfield brand, $62 \mathrm{~g}$ containing $50 \mathrm{~g}$ starch, 4 g protein $)^{1} 27$ made up with $200 \mathrm{ml}$ hot water; with $200 \mathrm{ml}$ cold water to drink. Each substrate was taken on three separate occasions with either m1099 50 mg, o1248 $20 \mathrm{mg}$ or a placebo of identical appearance at the start of the meal. These doses were chosen to be equipotent on the basis of the results of the animal studies..$^{23-25}$ Tablets were given double blind in randomised order. The three tests for each substrate were done within a three week period with at least five days washout period between tests. Subjects followed the same routine of activity and meals on the day before each test, fasted overnight and took test meals at the same time on each occasion. Subjects were seated at rest for the first two hours of each test and were then allowed restricted activity over the next two hours. None of the subjects had any history of allergy or drug intolerance or had taken antibiotics in the previous month. No other medication was taken in the test period.

Finger prick blood samples were taken using Autolets (Owen Mumford Ltd, Woodstock, Oxon) into bottles containing $(0.2 \mathrm{mg}$ sodium fluoride and $0.6 \mathrm{mg}$ potassium oxalate for measurement of blood glucose, using an enzymatic method detected by an oxygen electrode (Yellow Springs Instruments, Model 27) ${ }^{28}$ Finger prick samples were taken every 15 minutes from (0) to 60 minutes and then at 90 and 120 minutes. Venous blood was taken before and three hours after the start of each study for measurement of haematological indices and for biochemical measurements including urea, electro- 
lytes, calcium, phosphate, liver function tests, amylase, urate, cholesterol, and triglyceride.

End expiratory breath samples were taken using a modified Haldane-Priestley tube ${ }^{29}$ for the measurement of breath hydrogen concentration with a hydrogen electrode (Exhaled Hydrogen Monitor, GMI Medical Ltd. Renfrew). End expiratory samples were taken every 15 minutes from 0 to 150 minutes and then every 30 minutes to 240 minutes. A rise in breath hydrogen was taken as an indirect indication of malabsorption of carbohydrate.

A proportional relationship between the amount of carbohydrate malabsorbed and the hydrogen concentration in expired alveolar air has been reported. ${ }^{3(1-32}$ In an attempt to calibrate each subject's malabsorption, a separate study was done in which end expiratory breath hydrogen concentration was measured after $25 \mathrm{~g}$ of the non-absorbable sugar lactulose. The ratio of the integrated breath hydrogen response (area under the curve) from the test meal to that from $25 \mathrm{~g}$ lactulose was used to estimate the amount of carbohydrate malabsorbed in the experimental situation for each individual.

Any symptoms or adverse reactions during the 24 hours after dosing were recorded by the subjects. The symptoms of distension, flatulence and loose motions which would be expected to be associated with malabsorption of carbohydrate were each recorded on a numerical scale of 0 (absent), 1 (mild), 2 (moderate) or 3 (severe).

DOSE RESPONSE STUDY

In pilot studies sucrose absorption was found to be inhibited more than that of the other substrates in the presence of the inhibitors. In therapeutic use this would be the limiting substrate because it would be malabsorbed at lower inhibitor dose levels than other substrates. For this reason sucrose was used as the substrate in the dosage studies.

Six different healthy male subjects (mean age 28 years (23-30); $106 \%$ (98-121) desirable weight) took $50 \mathrm{~g}$ sucrose in $400 \mathrm{ml}$ water on seven occasions. They took the following doses of inhibitors: $\mathrm{m} 109912 \cdot 5,25$ or $50 \mathrm{mg}$; o1248 5,10 or $20 \mathrm{mg}$; or a placebo of identical appearance, double blind in randomised order. All other experimental details were as described above.

Statistical analysis was done using Student's $t$ test. Values given are means \pm standard errors. The studies had the approval of the Ethics Committee of the Brent Health Authority.

\section{Results}

SUBSTRATE SPECIFICITY

Both inhibitors abolished the postprandial glycaemic rise after sucrose $50 \mathrm{~g}$ and resulted in a considerable rise in breath hydrogen concentration from 45 minutes onwards. The results are shown in Figure 2 together with the mean symptom scores during the 24 hours after dosing for distension (D). flatulence $(F)$ and loose motions (LM) for the two different inhibitors and placebo taken with sucrose. None of those with loose motions opened their bowels in the first two hours after dosing. The symptoms reported after o1248 were more severe than those after $\mathrm{m} 1099$. Breath hydrogen concentrations were also higher after ol248, though the differences between individual times or in the areas under the curves were not significantly different.

The effects seen after maltose were markedly different (Fig. 3). The postprandial glycaemic rise was reduced considerably by $\mathrm{m} 1099$ but 01248 had no significant effect. There was a small rise in breath hydrogen after maltose with m1099 but the symptoms reported were mild. Breath hydrogen levels and symptoms after o1248 and maltose were the same as after the placebo with maltose.

The postprandial glycaemic rise after starch was reduced moderately by o1248 and markedly by m1099 (Fig. 4). There was a small, late rise in breath
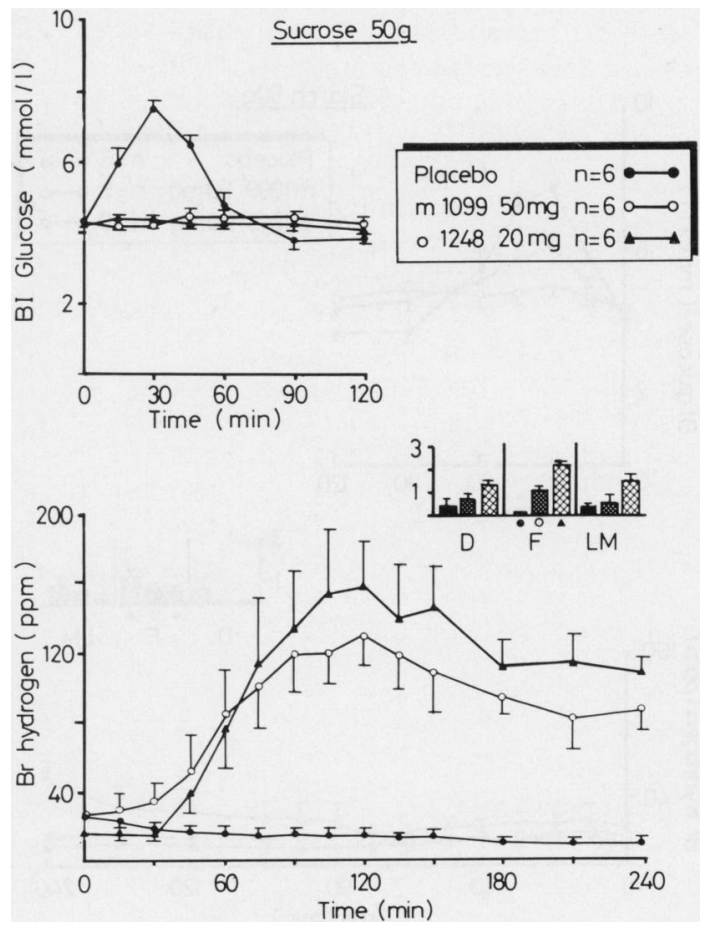

Fig. 2 Blood glucose and breath hydrogen responses after sucrose $50 \mathrm{~g}$ with placebo, mlog9 or ol248. Mean symptom scores for distension $(D)$, flatulence $(F)$ and loose motions (LM). (Glucose: I mmol/l $\approx 18 \mathrm{mg} / 10() \mathrm{ml}$ ). 


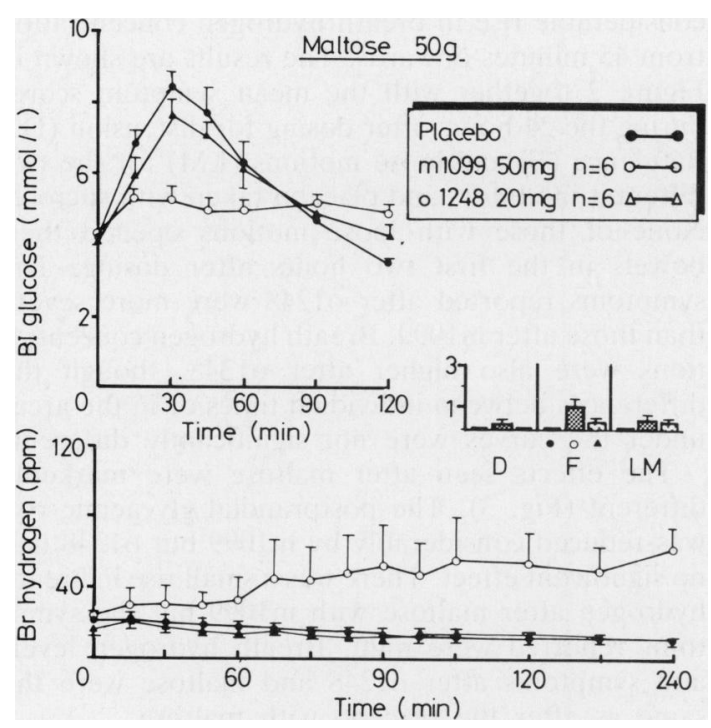

Fig. 3 Blood glucose and breath hydrogen responses after maltose $50 \mathrm{~g}$ with placebo, m1099 or o1248. Mean symptom scores for distension $(D)$, flatulence $(F)$ and loose motions $(L M)$. (Glucose: I mmolll $\approx 18 \mathrm{mg} / 100 \mathrm{ml}$ ).
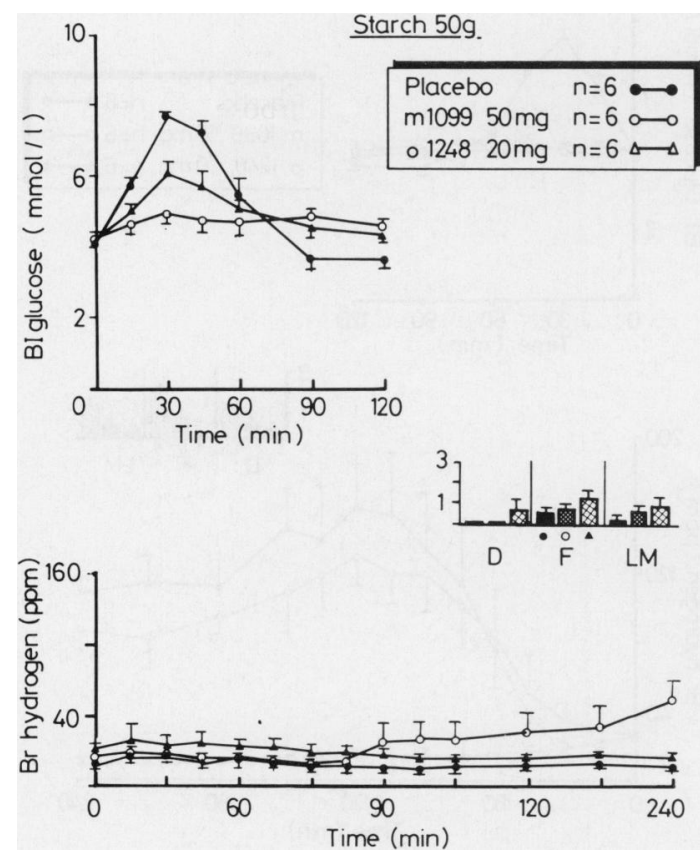

Fig. 4 Blood glucose and breath hydrogen responses after starch $50 \mathrm{~g}$ with placebo, m1099 or ol248. Mean symptom scores for distension $(D)$, flatulence $(F)$ and loose motions (LM). (Glucose: $1 \mathrm{mmol} / \mathrm{l} \approx 18 \mathrm{mg} / 100 \mathrm{ml}$ ). hydrogen after m1099 but not after o1248. The generally mild symptoms experienced were not significantly different between treatments and may well be a consequence of the bulk of the semisolid starch meal.

The amounts of the substrates which were malabsorbed in the presence of the two inhibitors, as calculated by the ratio of areas under the breath hydrogen curves, are shown in Table 1 .

DOSE RESPONSE

The effects of the three different dose levels of m 1099 on postprandial glycaemia after $50 \mathrm{~g}$ sucrose are shown in Figure 5 compared with the rise after

Table 1 Amount of carbohydrate malabsorbed $(g)$ calculated from hydrogen production with $25 \mathrm{~g}$ lactulose

\begin{tabular}{llcl}
\hline \multicolumn{4}{c}{ Substrate } \\
& Sucrose $50 \mathrm{~g}$ & Maltose $50 \mathrm{~g}$ & Starch $50 \mathrm{~g}$ \\
\hline & & $16 \pm 9$ & $5 \pm 4$ \\
$\mathrm{~m} 109950 \mathrm{mg}$ & $38 \pm 4$ & $0 \pm 1$ & $3 \pm 1$ \\
\hline $0124820 \mathrm{mg}$ & $49 \pm 8$ & 0 & \\
\hline
\end{tabular}
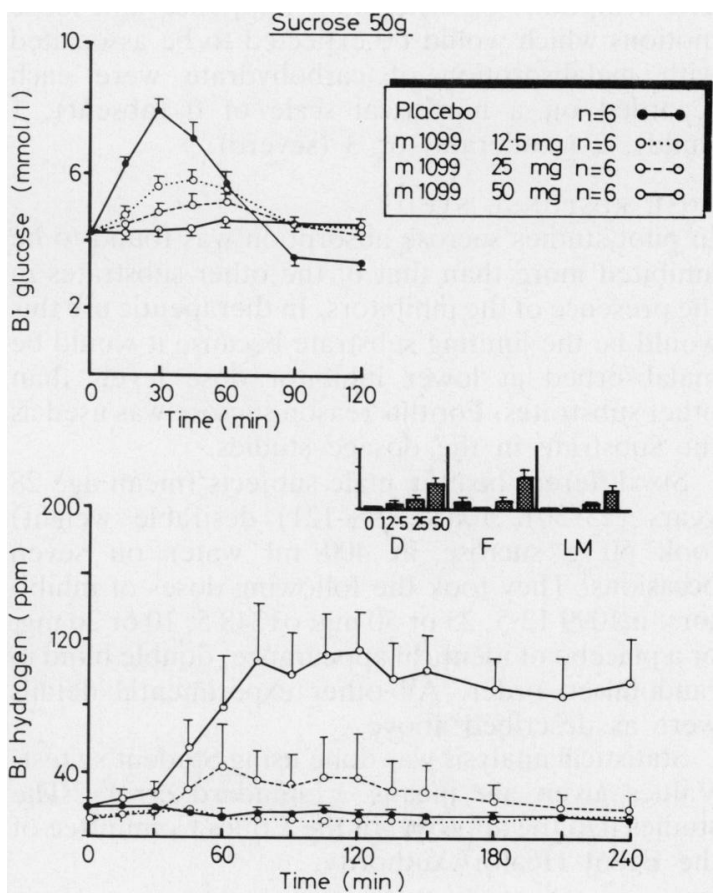

Fig. 5 Blood glucose and breath hydrogen responses after sucrose $50 \mathrm{~g}$ with placebo or m1099, $12.5 \mathrm{mg}, 25 \mathrm{mg}$ or $50 \mathrm{mg}$. Mean symptom scores for distension (D), flatulence $(F)$ and loose motions (LM). (Glucose: $1 \mathrm{mmol} / \mathrm{l} \approx 18 \mathrm{mg} / 100 \mathrm{ml}$ ). 
sucrose with placebo. With increasing dose the postprandial rise is reduced and the peak delayed. The low dose $(12.5 \mathrm{mg})$ caused no rise in breath hydrogen and no symptoms. The intermediate dose ( $25 \mathrm{mg}$ ) caused a slight rise in breath hydrogen but negligible symptoms. The high dose had similar effects in terms of breath hydrogen release and symptoms as had been found in the first study.

Even the lowest dose of o1248 (5 mg) caused a marked reduction in postprandial glycaemia, a moderate rise in breath hydrogen and some distension and flatulence. The $10 \mathrm{mg}$ and $20 \mathrm{mg}$ doses almost abolished the postprandial glycaemic rise, caused marked evolution of hydrogen and symptoms of similar severity at both dose levels (Fig. 6). The results at $20 \mathrm{mg}$ were closely similar to those found with the first group of subjects in the substrate specificity study.

The amounts of the $50 \mathrm{~g}$ sucrose load which were malabsorbed in the dose response study, as calculated by the ratio of areas under the breath hydrogen curves, are given in Table 2. Both compounds were well tolerated by all subjects at all
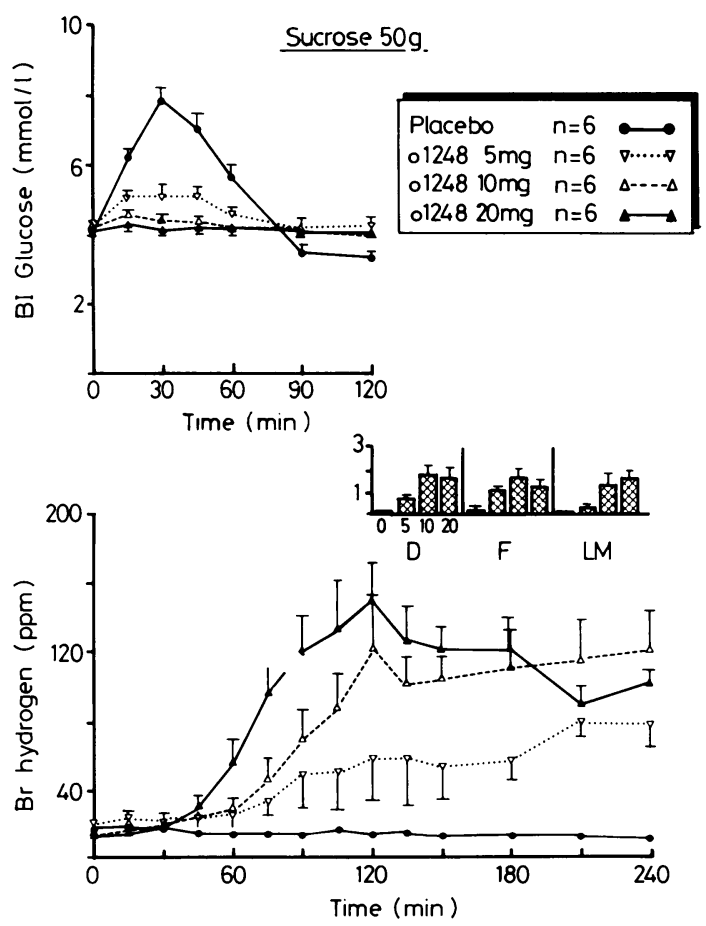

Fig. 6 Blood glucose and breath hydrogen responses after sucrose $50 \mathrm{~g}$ with placebo or o1 $248,5 \mathrm{mg}, 10 \mathrm{mg}$ or $20 \mathrm{mg}$. Mean symptom scores for distension $(D)$, flatulence $(F)$ and loose motions (LM). (Glucose: $1 \mathrm{mmol} / \mathrm{l} \approx 18 \mathrm{mg} / \mathrm{l}(00 \mathrm{ml}$ ).
Table 2 Amount of sucrose malabsorbed (g) from $50 \mathrm{~g}$ load at different inhibitor doses, calculated from hydrogen production with $25 \mathrm{~g}$ lactulose

\begin{tabular}{llrrrr}
\hline $\mathrm{m} 1099$ & $12 \cdot 5 \mathrm{mg}$ & $0 \pm 1$ & 01248 & $5 \mathrm{mg}$ & $13 \pm 4$ \\
& $25 \mathrm{mg}$ & $4 \pm 4$ & & $10 \mathrm{mg}$ & $24 \pm 4$ \\
& $50 \mathrm{mg}$ & $24 \pm 6$ & & $20 \mathrm{mg}$ & $30 \pm 4$ \\
\hline
\end{tabular}

dose levels. The only symptoms of any severity which were reported were the predicted ones associated with the effects of fermentation of malabsorbed carbohydrate and osmotic diarrhoea. A few minor symptoms, such as headache and tiredness, were reported but these ocurred as frequently in the placebo studies as after the inhibitors. There were no abnormalities of haematology or biochemistry found either before or after any of the tests in any of the volunteers, nor were there any consistent differences between the preand post-test values in any study.

\section{Discussion}

The results show that both these inhibitors are very effective in reducing postsucrose glycaemia. o1248 $20 \mathrm{mg}$, however, has a relatively small effect on poststarch glycaemia and no effect on postmaltose glycaemia. The effects of o1248 are similar to those reported previously with acarbose $200 \mathrm{mg} .^{.1}$ In contrast, glycaemia after maltose and starch is reduced by $\mathrm{m} 109950 \mathrm{mg}$ very effectively without appreciable malabsorption being caused. The differences in substrate specificity suggest that there may well be differences in the inhibitors' enzyme specificity in the intact gut. Both inhibitors are obviously effective against sucrase and m1099 appears to be effective against brush border maltases, other than sucrase, whereas o1248 seems to have negligible effect there. Inhibition of brush border maltase activity by m 1099 would explain the reduction in glycaemia after both maltose and starch but the lack of effect of o1248 on maltose absorption suggests that its effect on starch absorption must be at a different level. These observations are in keeping with the findings of in vivo intestinal perfusion studies in the rat, ${ }^{2.3}$ but they contrast with the results of Lembcke et $a^{22}$ who found that in vitro o1248 was as potent an inhibitor of isolated glucoamylase and maltase from mucosal homogenates as was m1099. Because maltose and maltooligosaccharides are end products of amylase digestion of starch, this suggests that the definite reduction of poststarch glycaemia by o1248 cannot be explained fully by a specific effect on brush border 
maltases. It must therefore be due in part to an inhibitory effect on luminal amylase activity of whatever source. In vitro studies with purified $\alpha$-amylase, however, have shown negligible inhibition of enzyme activity by m 1099 or o1248 (Bayer AG, unpublished observations). The explanation of this paradox is not clear but may lie in the fact that both $\alpha$-dextrinase and glucoamylase are active in hydrolysing malto-oligosaccharides with chain lengths up to nine or more glucose residues. These enzymes may contribute some 'amylase-like' activity to digestion of starch already partly broken down to shorter chain lengths in preparation. HPLC analysis $^{33}$ of the potato, as eaten by the subjects. however, showed that less than $1 \%$ of the carbohydrate present consisted of chains of less than eight glucose residues.

The doses used in the substrate specificity studies were based on intestinal perfusion studies in the rat in which these doses were equipotent in inhibiting the disappearance of luminal sucrose. ${ }^{2.3-25}$ As the inhibitory effect of these doses appears to be almost total after sucrose $50 \mathrm{~g}$, it is difficult to be sure whether this is a true equivalence in man. The dose response studies suggest that the high dose $(20 \mathrm{mg})$ of 01248 was much more potent in man in inhibiting sucrase activity than was the high dose $(50 \mathrm{mg}$ ) of m1099.

The potent sucrase inhibitory effect of both inhibitors has resulted in almost complete malabsorption of the carbohydrate load with its associated symptoms. The differences between the calculated amounts of sucrose malabsorbed in the presence of m1099 $50 \mathrm{mg}$ and $0124820 \mathrm{mg}$ in the two study groups are because of considerable individual variations in breath hydrogen evolution after lactulose and the inherently limited precision of this indirect test. ${ }^{34}$ These results must be treated with considerable caution, however, they have some value in giving an indication of the scale of malabsorption produced and the proportions for the two inhibitors are the same for both groups. There was some evidence of malabsorption of maltose with m1099 but not with o1248, though few symptoms were reported with either. There was no breath hydrogen evidence of starch malabsorption with either inhibitor but some symptoms were reported. Intestinal transit of the starch meal was probably much slower than that of the sugar solutions. ${ }^{32}$ Hydrogen evolution as an indication of malabsorption may thus have occurred later than the four hour collection period, as is hinted by the late rise in breath hydrogen after o1248. The volume of the meal and the dietary fibre present in the potato may both have contributed to symptoms reported over the 24 hour period. The amounts of hydrogen evolved after o1248 $20 \mathrm{mg}$ with sucrose were similar to those after acarbose $200 \mathrm{mg}$ with sucrose. Like acarbose, o1248 did not cause malabsorption of maltose or starch. " Despite the limitations of the technique, the dose response studies suggest that the amount of sucrose malabsorbed was broadly dose related. It seems that by using a lower dose of $\mathrm{ml}(099$ it is possible to regulate post-sucrose glycaemia without causing malabsorption, as was found with acarbose $50 \mathrm{mg} .{ }^{\prime \prime}$ and it seems likely that an even lower dose of o1248 than $5 \mathrm{mg}$ would have a similar effect. It is not only therapeutically undesirable to produce malabsorption of carbohydrate but in the regulation of diabetes it is essential to be confident that all carbohydrate that has been ingested is being absorbed and not lost to fermentation in the colon. Because sucrose is the most sensitive substrate for this, this is bound to be the limiting factor, unless it is totally excluded from the diet.

Maltose is not a commonly ingested dietary carbohydrate but is important in these studies because it is a major luminal digestion product of starch that is then hydrolysed at the brush border. The results suggest that the inhibitory effect of ml(099 on poststarch glycaemia in man could be explained entirely by inhibition of maltase activity. In these studies, however, o1248 had negligible effect on maltose absorption but had a greater effect on starch absorption. This suggests that, despite the unpublished in vitro data, the compound appears to have some inhibitory effect on amylase activity in vivo in man.

The symptoms reported in these studies only occurred in the presence of the indirect breath hydrogen evidence of malabsorption of carbohydrate. In circumstances where carbohydrate uptake was slowed but complete, the only symptoms reported were minimal and occurred as frequently on placebo as they did in the presence of the inhibitors. It seems possible therefore to regulate the rate of carbohydrate uptake using these inhibitors and to reduce the postprandial glycaemic peak without causing undesirable malabsorption or symptoms. These compounds appear to have a therapeutic potential in the regulation of blood glucose in patients who have an impairment of carbohydrate metabolism and, in particular, in diabetes. The inhibitory properties of o1248 are similar to those of acarbose but it appears to be 10 times more potent than acarbose. The inhibitory profile of $m 1099$ is appreciably different and its potency seems to lie between those of acarbose and o1248. The results suggest that m1099, with a broader spectrum of substrate specificity, may be a more effective therapeutic agent. They also suggest that, even if sucrose is excluded rigorously from the diet, a dose 
of m1099 $25 \mathrm{mg}$ at mealtimes may be sufficient to regulate postprandial glycaemia. In addition to their therapeutic potential, these derivatives of deoxynojirimycin have considerable scientific interest in that they provide a reversible experimental model of intestinal enzyme deficiency syndromes both in animals and man.

RHT was a Wellcome Senior Research Fellow in Clinical Science. Funding and assistance from The Wellcome Trust and the Pharmaceutical Division, Bayer UK Ltd are gratefully acknowledged. Supplies of BAY m1099, o1248 and placebo tablets were kindly provided by Bayer AG Leverkusen.

\section{References}

1 Jenkins DJA, Wolever TMS, Taylor RH, et al. Glycaemic index of foods: a physiological basis for carbohydrate exchange. Am J Clin Nutr 1981; 34: 362-66.

2 O`Dea K, Nestel PJ, Antonoff L. Physical factors influencing postprandial glucose and insulin responses to starch. Am J (lin Nutr 1980; 33: 76()-65.

3 Crapo PA, Reaven G, Olefsky J. Plasma glucose and insulin responses to orally administered simple and complex carbohydrates. Diabetes 1976; 25: 741-47.

4 Fajans SS, Floyd JC, Knopf RF, Conn JW. Effect of amino acids and proteins on insulin secretion in man. Rec Prog Horm Res 1967; 23: 617-62.

5 McSwiney BA, Spurrell WR. The effect of fat on gastric motility. J Physiol 1935; 84: 41-49.

6 Jenkins DJA, Wolever TMS, Leeds AR, et al. Dietary fibres, fibre analogues and glucose tolerance: importance of viscosity. Br Med J 1978; 1: 1392-94.

7 Schmidt DD, Frommer W, Junge B, et al. $\alpha$-glucosidase inhibitors: new complex oligosaccharides of microbial origin. Naturwissenschaften 1977; 64: 535-36.

8 Truscheit E. Frommer W, Junge B. Müller L, Schmidt DD, Wingender W. Chemistry and biochemistry of microbial $\alpha$-glucosidase inhibitors. Angewandte Chemie Int Ed Engl 1981: 20: 744-61.

9 Caspary WF, Graf SD. Inhibition of human intestinal $\alpha$-glucosidehydrolases by a new complex oligosaccharide. Res Exp Med (Berl) 1979; 175: 1-6.

10) Barker HM, Taylor RH. Maltase and sucrase inhibition by acarbose: a paradoxical effect in vivo. $\mathrm{Br} J$ Pharmacol 1983; 78: 65p.

11 Jenkins DJA, Taylor RH, Goff DV, et al. Scope and specificity of acarbose in slowing carbohydrate absorption in man. Diabetes 1981; 30: 951-54.

12 Taylor RH, Barker HM. Reversibility of sucrase inhibition by acarbose in in vivo perfusion of the rat jejunum. [Abstract] Gut 1982: 23: A913.

13 Taylor RH, Barker HM. Recovery of intestinal sucrase and maltase activity after inhibition by acarbose in vivo. Clin Sci 1983; 64: 52P.

14 Taylor RH, Barker HM. Intestinal glucose and fructose absorption is unimpaired when sucrase is inhibited by acarbose. [Abstract] Proc Nutr Soc 1983; 42: 89A.
15 Barker HM, Canfield JE, Taylor RH. Stable doserelated partial inhibition of sucrase activity can be produced by a glycoside hydrolase inhibitor. Clin Sci 1983: 65: 9-10P.

16 Taylor RH, Barker HM, Canfield JE. Intestinal sucrase inhibition by a reversible inhibitor: initial and steady state kinetics. Gastroenterology 1983; 84: 1333.

17 Inouye S, Tsuruoka T, Niida $T$. The structure of nojirimycin, a piperidinose sugar antibiotic. $J$ Antiobiotics 1968; 19: 288-92.

18 Inouye $\mathrm{S}$. Tsuruoka T, Ito T, Niida T. Structure and synthesis of nojirimycin. Tetrahedron 1968; 24: 212544.

19 Schmidt DD, Frommer W, Muller L, Truscheit E. Glucosidase-Inhibitoren aus Bazillen. Naturwissenschaften 1979; 66: 584-85.

20 Niwa $T$. Inouye $S$, Tsuruoka $T$, Koaze $Y$, Niida $T$. Nojirimycin as a potent inhibitor of glucosidase. Agric Biol Chem 1970; 34: 966-68.

21 Reese ET, Parrish FW, Ettlinger M. Nojirimycin and d-glucono-1.5-lactone as inhibitors of carbohydrases. Carbohydrate Res 1971; 18: 381-88.

22 Lembcke B. Fölsch UR, Creutzfeldt W. Effect of 1deoxynojirimycin derivatives on small intestinal disaccharidase activities and on active transport in vitro. Digestion 1985; 31: 120-27.

23 Taylor RH, Barker HM, Bowey EA, Canfield JE. Selective inhibition of intestinal disaccharide absorption by deoxynojirimycin-derived glycosidase inhibitors. Clin Sci 1984; 67: 41P.

24 Taylor RH, Barker HM, Bowey EA, Canfield JE. Intestinal monosaccharide transport is unimpaired by deoxynojirimycin-derived glycosidase inhibitors. Clin Sci 1984; 67: 63P

25 Taylor RH, Barker HM, Bowey EA, Canfield JE. Two selective inhibitors of intestinal carbohydrate absorption. [Abstract] Gut 1984; 25: A1155-56.

26 Metrop Life Insur Co. Desirable weights of adults. In: Diem K. Lentner C, eds. Documenta Geigy: scientific tables, 7th ed. Basle: J R Geigy, 1970: 712.

27 Jenkins DJA, Ghafari H. Wolever TMS, et al. Relationship between rate of digestion of foods and postprandial glycaemia. Diabetologia 1982; 22: 450-55.

28 Clark LC. A polarographic enzyme electrode for the measurement of oxidase substrates. In: Kessler M, Bruley DF, Clark LC, Lubbers DW, Silver IA, Strauss J, eds. Oxygen supply. Baltimore: University Park Press, 1973: 120)-28.

29 Metz G, Gassull MA, Leeds AR, Blendis LM, Jenkins DJA. A simple method of measuring breath hydrogen in carbohydrate malabsorption by end-expiratory sampling. Clin Sci Mol Med 1976; 50: 237-40.

30) Bond JH, Levitt MD. Use of pulmonary hydrogen measurements to quantitate carbohydrate absorption. $J$ Clin Invest 1972; 51: 1219-25.

31 Caspary WF. Sucrose malabsorption in man after ingestion of $\alpha$-glucosidehydrolase inhibitor. Lancet 1978; i: 1231-33.

32 Read NW, Miles CA, Fisher D, et al. Transit of a meal through the stomach, small intestine and colon in normal subjects and its role in the pathogenesis of diarrhoea. Gastroenterology 1980; 79: 1276-82. 
33 Grimble GK, Barker HM, Taylor RH. Chromatrographic analysis of sugars in physiological fluids by post-column reaction with cuprammonium - a new and highly sensitive method. Anal Biochem 1983; 128: $422-28$.
34 Lembcke B, Fölsch UR, Caspary WF, Ebert R, Creutzfeldt $\mathrm{W}$. Influence of metronidazole on the breath hydrogen response and symptoms in acarboseinduced malabsorption of sucrose. Digestion 1982; 25: 186-93. 